\title{
Critical Thinking as Grounds of Socially Responsible Communication
}

\author{
Iveta Linina \\ Turiba University \\ Riga, Latvia \\ iveta.linina@turiba.lv
}

\author{
Velga Vevere \\ EKA University of Applied Sciences \\ Riga, Latvia \\ velga.vevere@gmail.com
}

\begin{abstract}
Companies and individuals are willing to introduce the principles of social responsibility in their everyday working practices, still, in order to accomplish this and to have real gains for the company and society, the concept of social responsibility has to be understood in the broadest sense. This understanding is based on critical information processing or critical thinking. Information can be obtained through reflection, observation, communication, experience, etc. The aim of the research is to study the factors that influence the basic principles of critical thinking formation, which are the basis of socially responsible communication. The authors employ the monographic method for charting the theoretical framework, the survey to research respondent's' ability to evaluate information critically and to make socially responsible decisions. As the result of research the authors conclude that development of the critical thinking competences can raise the level of social responsibility on the individual and societal level.
\end{abstract}

Keywords - Communication; socially responsible communication; critical thinking; critical information processing

\section{INTRODUCTION}

Communication process, in general, is playing more and more significant role in contemporary society. The process is facilitated by the advancement of new technologies and increasing competition within global business environment. Responsible communication is most often associated with conveying the truth in a manner which does not try to manipulate [1]. The responsible communication presupposes such aspects as accessibility, responsiveness and transparency. However, conducting a responsible communication process actually means much more and should also focus on information selection, processing and relaying it others in the appropriate form. A company which strives to become an excellent communicator should carefully manage its entire range of customer touch points and focus on increasing both the actual and the perceived value of its communication process. It pertains any company regardless its size and legal status (private, public, et.), to every management level - from client managers to company CEOs. This brings forth the question of business education, namely, teaching students the responsible communication fundamentals. The novelty of our approach is to relate students' business communication competence to their critical thinking ability.

The role of critical thinking in the contemporary society is as significant as never before since with the process of globalization the speed of business operations increases immensely, that, in its turn involves complex flow of information and necessity to make decisions on all managerial levels, often without the previous experience in the field. This calls for a special type of skills, the one of critical thinking - the mental process of analysis and evaluation information, recognition of the fake content, misleading data, etc. The source of information can be experience, reflection, observation, communication, etc., as well as study process. According to the research of Pearson Education [2], the highest rated skills today are the following: good analysis and problem-solving skills; good judgment and decision making; good overall job performance; the ability to evaluate the quality of information presented; creativity; job knowledge; and the potential to move up within the organization. Critical thinking, perhaps more than any other business skill set, can make the difference between success and failure. Particularly the business world has increasingly stressed the need for critical thinking in graduates for handling large volumes of information in decision-making, with increased competition and pace of change leading to a need for a more strategic outlook and more innovative approaches to processes and products. The business education plays a special role in developing critical thinking skills. In 
addition, the critical thinking becomes a matter of a special importance during the crisis situation, such as Covid-19 pandemic, when many unconventional and nontrivial decisions are to be made, the information are to be sorted out; the new learning and communication methods are to be acquired. Besides that, more than ever there exists necessity for skills to detect the fake news and different conspiracy theories, to check the information sources. The authors of the current research are daily involved with these issues being professors at the private universities in Latvia, teaching such subjects as critical thinking, problem solving, international marketing and research methodology to business students of the bachelor, master and doctoral levels. The aim of the current research is to study the factors that influence the basic principles of critical thinking formation, which are the basis of socially responsible communication.

\section{MATERIALS AND METHODS}

Communication is an integral feature of human activities. Communication can be described as the process of transmitting and receiving ideas, information and messages. It is used to persuade; to influence relationships; to inform; and to share, discover and uncover information. It is important to recognize that it is a critical thinking fosters the communication and collaboration competence (i.e., information processing, fact checking, communication content, etc.), on one hand, while, on the other hand - the communication competence enhances the critical thinking; this is because communication is a dynamic interactive process that involves the effective transmission of facts, ideas, thoughts, feeling and values. Thus, it follows that development of communication skill is not a separate activity from problem solving, creativity, or collaborative learning, because the students will use communication skills for logical presentation of facts in oral or written form [3]. The concept of responsible communication in the current research is defined through the prism of values as defined in the ground breaking book by Mary C. Gentile “ Giving Voice to Values: How to Speak Your Mind When You Know What's Right” [4] and summarized by D. L. Remund [5]. Responsible communication means taking ownership of, and accountability for clear, candid, and consistent dialogue about values-based decisions. The ground rules of such communication include sincerity, relevance, continuity, clarity, prudence, tolerance, openness, prompt resolution, balance, and optimal timing [6]. All in all, the responsible communication, according to this approach means basically three things - accessibility, responsiveness and transparency. Accessibility breeds trust, and trust builds relationships,. In short, accessibility is often about information - receiving and sharing. Being accessible means staying adaptable to changing circumstances and sharing information as freely as possible. Responsiveness, on the other hand, stresses the dynamic character of communication - interaction with stakeholders regarding important issues and moral based decisions. Finally, the third concept of transparency describes sharing information, not having hidden agendas, and being forthright. In the example of information or data, being visible would mean being easily located and complete; being inferable, then, would mean being thorough enough to draw verifiable inferences. We can state that there exists distinct correlation between critical thinking and communication skills - the indicators of critical thinking are skills of formulating and analysing problems; providing viable arguments based on scientific evidence and developing a concise explanation; implementing evaluation which is accompanied by facts, principles or existing guidelines and drawing conclusions. Each and every of these indicators involves communication - relying information; responsible content formation and use of the means and techniques [7].

There is a variety of definitions of critical thinking depending on the field of application and its functions. Some value the reasoning process specific to critical thinking, while others emphasize the outcomes of critical thinking, such as whether it can be used for decision making or problem solving. Thus, for, example, D. F. Halpern [8] focuses on the outcome or utility aspect of critical thinking, in that critical thinking is conceptualized as a tool to facilitate decision making or problem solving in everyday life and business.

Other authors put their stress upon teaching and educational aspects and inclusion of the dedicated course in the curriculum. Because success in our technically advanced society requires critical thinking competence, and because education is the principal means of preparing students for an active and responsible life, it is imperative that educational establishments focus on fostering and developing the critical thinking skills. Nonis and Hudson [9] write about the developing skills of marketing students by the means of including specific themes and practical tasks in different courses (such as, marketing, management, market research, etc.). Among the recent studies we can mention the ones by R. Andrews [10], R. Barnett [11], K. Thomas and B. Lok [12].

Yet other researchers are engaged in the problem of assessment of the level of students' critical thinking, for example such authors as, A. S. Ünsar and E. Engin [13]; M. Karakoc [14]; B. Critchley [15]; A. Khalifa [16]; T. Laurer [17] and many others.

For the purpose of the current research we employ a definition proposed by the Foundation for Critical Thinking that describes the critical thinking as the "intellectually disciplined process of actively and skilfully conceptualizing, applying, analysing, synthesizing or evaluating information gathered from, or generated by, observation, experience, reflection, reasoning, or communication, as a guide to belief and actions" [18]. This definition comprises, in our opinion, the vital characteristics of this thinking mode, namely, the acquired (taught) abilities to work with information and apply results of reflection in the practice. In addition, the critical thinking involves the art of argument creation. This process is thoroughly described by T. Bowel and G. Kemp in their joint book "Critical thinking: a concise guide" [19]. The authors argue that it is very important to tell whether an 
argument is being given, exactly what the argument is about, and whether one ought to be persuaded by it.

R. Paul and L. Elder [20], on the other hand, presents a list of the characteristics of critical thinkers. These characteristics include the following activities: raising vital questions and problems, formulating them clearly and precisely; gathering and assessing relevant information, using abstract ideas to interpret it effectively; coming to well-reasoned conclusions and solutions, testing them against relevant criteria and standards; thinking openmindedly within alternative systems of thought, recognizing and assessing as need be, their assumptions, implications, and practical consequences; and, finally, communicating effectively with others in figuring out solutions to complex problems. Moreover, critical thinking requires the use of self-correction and monitoring to judge the reasonableness of thinking as well as reflexivity. Thus, critical thinking ability can be viewed as one of the most important components in $21^{\text {st }}$ century skill roadmap alongside with communication and collaboration, innovation, media literacy, technology literacy, productivity and accountability, leadership and responsibility [21].

The focus of the current article particularly is the relation between critical thinking and responsible communication.

Within the framework of this study, in order to find out respondents' use of critical thinking in evaluation of information, a traditional method was used - a survey was organized with the help of a questionnaire. Additional aspects researched were the following: students' ability to distinguish false information from true; their views on responsibility for disseminating false information. The respondents were full and part-time students from three Latvian universities, aged between 19 and 40. Preparation of the survey involved the following steps:

(1) Determining the standardization and degree of openness of the questionnaire. Taking into account the purpose of the survey and the characteristics of the respondents, the authors of the paper chose a standardized open questionnaire. This meant that all respondents were offered the same questions in the same order, which ensured an objective comparison of answers. The questions were selected with one answer variant according to the Likert scale in the 10-point system and other answer variants in the system.

(2) Determining the survey method. The authors of the paper chose the following option - the survey was created on the website "Google forms". The questionnaire was sent to the respondents via e-mail using the personal contacts of the authors. The questionnaires were filled out and 387 responses were recognized as valid for the current research. Students of all Latvian higher education institutions in 2020 were taken as census altogether 78548 students. At the $95 \%$ confidence level and 5\% error margin, the minimum sample size was calculated - 383 respondents [22].
(3) Determining the acquisition of the necessary information. For this purpose two focus group discussions were organized, as well as a pilot research. Taking into account the pilot study results, the questions on students' self-assessment regarding information evaluation and questions that allow to assess his / her true skills were prepared.

(4) Question wording. To avoid problems, the authors followed recommendations of the experts [23], [24], [25]: to use simple words and sentences; to avoid ambiguous words and questions; to avoid prompting questions; to avoid hidden alternatives; to make the questions are concrete.

(5) Sequence of questions. The sequence of questions is also an important step, as it affects the respondents' interest in answering questions accurately. In order to avoid such mistakes, the authors of the paper followed special recommendations: general questions were asked at the beginning, but specific questions were later; relatively difficult questions were placed in the second half of the questionnaire; questions on one topic were completed before moving on to the next topic.

(6) Determining the form of the answer. In order to be able to provide a quantitative assessment and perform an appropriate analysis in the case of one possible answer, the authors used a Likert scale with a ten-point rating, where 0 was no rating and 10 was very high. But in order to assess the respondents' true skills and social responsibility in case of providing false information, the ranking of students' agreement with a particular statement was performed.

(7) Statistical methods of processing and analysis of the survey results. Extensive statistical analysis was possible for the given questions. Using the SPSS program, the authors calculated the following indicators: the arithmetic mean $(\mathrm{X})$; the arithmetic mean standard error; median (Me); mode (Mo); amplitude of variation; standard deviation. For questions with possible multiple choice answers, the percentage of answers in the total sum of answer options was calculated. In order to find out whether there is a correlation between respondents' self-assessment and other factors, correlation coefficients were calculated.

\section{RESULTS AND DISCUSSION}

The responses were further processed and analysed. First, the main sources for information obtaining were clarified. In the authors' opinion, the information sources particularly can serve as one of the indicators for the truthfulness of information. After processing the answers, it could be seen that the main sources of information for respondents were the internet news portals (44\%), followed by the social networks (36\%), TV (13\%), information from peers $(5 \%)$ and other unidentified sources $(2 \%)$. When asked about the existence and number of accounts in social networks, the answers were the following: existence of one account was admitted by $3 \%$, two accounts by $21 \%$, three accounts by $18 \%$ of all respondents, but more than three by $58 \%$ of respondents. Social networks make it possible for users to share information, that, in its turn, can serve as an information source for followers. The shared information 
in some (or many) cases can be deemed as fake, still, sharing fakes does not presuppose any responsibility to society. Next, the issue of the students' self-assessment in recognizing false information was discussed (see Table 1). In this question, students rated their skills in recognizing false messages on a 10-point scale, where 0 meant that the student could not distinguish between a false message and a real one at all, and 10, where they could always do so.

TABLE 1 STUDENTS SELF-ASSESSMENT IN FAKE NEWS RECOGNITION

\begin{tabular}{|c|c|c|c|c|c|c|}
\hline Criterion & 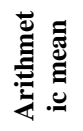 & 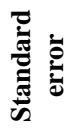 & & 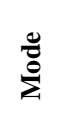 & 总 & 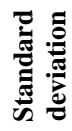 \\
\hline $\begin{array}{l}\text { Students' } \\
\text { self- } \\
\text { assessment } \\
\text { in } \\
\text { recognition } \\
\text { of fake } \\
\text { news }\end{array}$ & 7.22 & 0.85 & 8.00 & 8.00 & 8.00 & 2.54 \\
\hline
\end{tabular}

Analysing the obtained data, it can be concluded that students evaluated their skills in recognizing fake messages quite highly, because the arithmetic mean was 7.22. But if we looked at the range of variations, it was large, which showed that there were students who regarded themselves as being able to objectively assess their skills, namely, their low ability of false news recognition. As the median showed, the most common value was 8 , no student rated himself with 0 and 1 .

In order to find out whether there was a correlation between the respondents' self-assessment and the factors that indicated the reasons for not recognizing false information, a correlation coefficient was calculated. The authors' calculations of the correlation coefficient between the respondents' self-assessment (on a 10-point scale) and three factors - limited sources of true information, belief in distinctly populist personalities and recognition of worldrenowned Latvian scientists showed that the correlation existed, but it was not always very pronounced. A negative correlation coefficient indicates that when increasing one indicator, the other decreases, but positive, increasing one, the other increases. Very weak and weak correlation means that the level of the students' self-assessment is irrelevant to the factors that may affect the ability to recognize false information or the students' ability to objectively assess themselves in relation to the recognition of false information (see Table 2).

TABLE 2 CORRELATION COEFFICIENTS THAT SHOW THE RELATIONSHIP BETWEEN A STUDENT'S SELF-ASSESSMENT IN RECOGNIZING FALSE INFORMATION AND FACTORS THAT INDICATE A LACK OF ABILITY

\begin{tabular}{|l|c|}
\hline \multicolumn{1}{|c|}{ Indicators of fake news } & $\begin{array}{c}\text { Students' self-assessment in } \\
\text { fake news recognition }\end{array}$ \\
\hline $\begin{array}{l}\text { Number of information sources } \\
\text { used }\end{array}$ & -0.156 \\
\hline $\begin{array}{l}\text { Belief in populistic } \\
\text { personalities }\end{array}$ & 0.104 \\
\hline $\begin{array}{l}\text { Ability to recognize Latvian } \\
\text { scientists }\end{array}$ & -0.121 \\
\hline
\end{tabular}

The calculation of the correlation coefficients showed that the higher the students' self-esteem, the less information sources they use. As well as belief in highly populist well-known personalities, there was a weak but positive correlation with high self-esteem. A similar situation was observed with the recognition of scientists. The fewer scientists were recognized, the higher their skills in recognizing false news. These correlation coefficient calculations showed that students had major problems in objectively assessing their ability to distinguish false information from true information.

Respondents were also asked how much they agreed with the statement that they share information on social networks without being convinced of its truthfulness (see Figure 1).

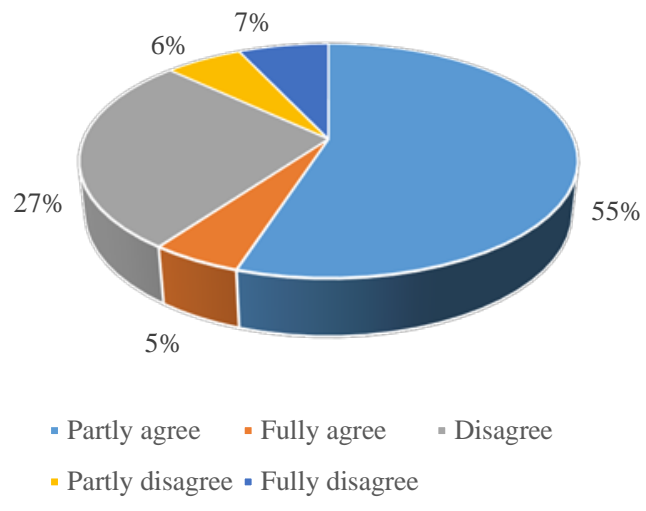

Fig. 1. Responses to the statement regarding sharing information without fully checking information.

The answers to this question made it clear that the majority, i.e., a total of $60 \%$ of respondents, partially or fully agreed with the statement that they shared news on social networks without being convinced of its truthfulness. Only $7 \%$ of respondents said they completely disagreed with the statement that they always share news without being sure of its content.

Finally, the respondents were asked whether the distributors of false information should be responsible for the consequences caused by this information (see Figure 2).

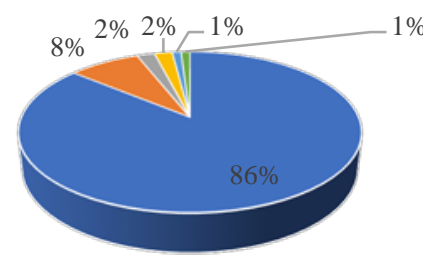

$$
\begin{aligned}
& \text { - Yes } \\
& \text { - No } \\
& \text { - It doesn't matter } \\
& \text { - Yes, but evaluating effect } \\
& \text { - Yes, if a person holds high position } \\
& \text { - Depending on situation }
\end{aligned}
$$

Fig. 2. Responsibility for sharing false information 
Environment. Technology. Resources. Rezekne, Latvia Proceedings of the $13^{\text {th }}$ International Scientific and Practical Conference. Volume 1, 149-154

Most of the respondents (86\%) answered affirmatively, several with the remarks that it depended on the situation, or if a person held a high position, but only $8 \%$ answered no.

\section{CONCLUSIONS}

During the survey the main sources of information of the respondents were identified and it was concluded that they are Internet news portals (44\%), followed by social networks (36\%), TV (13\%), information from peers (5\%) and other unidentified sources (2\%). In addition, 59\% of respondents have profiles on more than 3 social networks.

In the course of the survey it was found out that students, when evaluating their ability to distinguish false information from the true one, have assessed themselves relatively high - with the arithmetic mean 7.22.

Calculations of the correlation coefficient showed that respondents were most likely not able to assess their skills in recognizing false information, the more limited the students' information sources and the less they were able to recognize the world-class Latvian scientists, the higher was their self-evaluation. As well as those whose self-esteem was higher, trusted more the populistic personalities. But as the correlation appeared to be weak, the conclusion could not be fully applied to all respondents.

Summarizing all information obtained in the study, it can be concluded that students have problems with objective self-assessment of recognizing false information, and the majority, $60 \%$ of respondents, agree in part or in full with the statement that they share information on social networks without being convinced. Only $7 \%$ of respondents said they completely disagree with the statement that they always share news without being sure of its content. It is very important to understand that sharing false information (fake news) can bring about consequences. Therefore, the authors of the current research stress the necessity to develop socially responsible communication skills among students and general public.

Sharing fake news can have consequences. In the study, it was very important to understand the opinion of the respondents or to express or share false information, there should also be responsibility for it. Most of the respondents (86\%) answered affirmatively, but several with the remarks that depending on the situation, or if a person holds a high position, but only $8 \%$ answered no. The authors of the current research believe that it would be necessary to work out the code of ethics (the voluntary code of behaviour) for the users of social media to reduce sharing of false and unverified information.

Research points at the need for critical thinking skills for both students and general public that would be basis of socially responsible communication.

\section{REFERENCES}

[1] R. L. Johannesen, K. S. Valde and V. E. Whedbee, Ethics in Human Communication. Long Grove, Il.: Waveland Press, Inc., 2008.

[2] Pearson 2013 results. [Online]. Available: https://www.pearson.com/news-and- research/announcements/2014/02/pearson-2013-results.html [Accessed: March 19, 2021].

[3] S. K. W. Chu and others, 21st Century Skills Development Through Inquiry-Based Learning. Singapore: Springer Science+Business Media, 2017.

[4] M. C. Gentile, Giving Voice to Values: How to Speak Your Mind When You Know What's Right. New Have and London: Yale University Press, 2010.

[5] D. L. Remund, The art of responsible communication. Leading with values every day. New Yourk: Business Expert Press, 2015.

[6] B. Dresp-Langley, "The Communication Contract and Its Ten Ground Clauses,” Journal of Business Ethics, vol. 87, no. 3 2009, pp. 415-436.

[7] S. K. Bandyopadhyay and J. Szostek, „Thinking critically about critical thinking: Assessing critical thinking of business students using multiple measures," The Journal of Education for Business, vol. 94, no.4, 2018, pp. 1-12, DOI: 10.1080/08832323.2018.1524355

[8] D. F. Halpern, Halpern Critical Thinking Assessment manual. Vienna, Austria: Schuhfried GmbH, 2010.

[9] S. A. Nonis and G. I. Hudson, "Developing and assessing critical thinking skills in marketing students: The power of making explicit problem-solving processes," Journal of Education for Business, vol. 94, no. 3, 2019, pp. 195-203, https://doi.org/10.1080/08832323.2018.1504737

[10] R. Andrews, "Critical Thinking and/or Argumentation in Higher Education," in The Palgrave Handbook of Critical Thinking in Higher Education, New York: Palgrave Macmillan, 2015, pp. 4962.

[11] R. Barnett, “A Curriculum for Critical Being,” in The Palgrave Handbook of Critical Thinking in Higher Education, New York: Palgrave Macmillan, 2015, pp. 63-76.

[12] K. Thomas and B. Lok, "Teaching Critical Thinking: An Operational Framework," in The Palgrave Handbook of Critical Thinking in Higher Education, New York: Palgrave Macmillan, 2015, pp 93-106.

[13] A. S. Ünsar and E. Engin, “A case study to determine critical thinking skills of university students, " Procedia - Social and Behavioral Sciences, vol. 75, 2013, pp. 563 - 569, https://doi.org/10.1016/j.sbspro.2013.04.061

[14] M. Karakoc, “The Significance of Critical Thinking Ability in terms of Education, " International Journal of Humanities and Social Science, vol. 6, no. 7, July 2016, pp. 81-84.

[15] B. Critchley, "Critical Thinking in Business Education," Investigations in university teaching and learning, vol. 7, spring 2011, 5-15.

[16] A. Khalifa, "Rethinking the Current Dominant Approach to Business School Strategy,” European Business Review, vol. 22, no. 6, 2009, pp. 591-607, https://doi.org/10.1108/09555341011082907

[17] T. Laurer, “Teaching Critical Thinking Skils Using Course Content Material: a reversal of roles,” Journal of College Science Teaching, vol. 34, no. 6, 2005, pp. 34-37.

[18] The Foundation for Critical Thinking. [Online] Available: https://www.criticalthinking.org/pages/defining-criticalthinking/766 [Accessed 20 March, 2021].

[19] T. Bowell and G. Kemp, Critical thinking: A Concise Guide. London and New York: Routledge, 2015.

[20] R. Paul and L. Elder, Critical Thinking Tools for Taking Charge of Your Professional and Personal Life. Upper Saddle River, New Jersey, Pearson Education, Inc., 2014.

F. A. Yusuf and E. A. Adeoye, "Developing Critical Thinking and Communication Skills in Students: Implications for Practice in Education,” African research review, vol. 6, no. 1, 2012, pp. 311324, http://dx.doi.org/10.4314/afrrev.v6i1.26

[21] H. Hasanah and M. N. Malik, M. N., "Blended learning in improving students' critical thinking and communication skills at University," Cypriot Journal of Educational Science, vol. 15, no. 5, 2020, pp. 1295 - 1306, https://doi.org/10.18844/cjes.v15i5.5168 
Iveta Linina, et al. Critical Thinking as Grounds of Socially Responsible Communication

[22] I. Arhipova and S. Bāliṇa, Statistics in Economy and Business [Statistika ekonomikā un biznesā]. Riga: Datorzinību centrs, 2006.

[23] S. L. Payne, The Art of Asking Questions. Princeton: Princeton University Press, 1978.
[24] P. L. Erdos, Professional Mail Surveys. Melburne, Fla.: Robert E.Krieger Publishing, 1983. 